Cite this: Polym. Chem., 2014, 5, 204

\section{Critically evaluated rate coefficients in radical polymerization -7 . Secondary-radical propagation rate coefficients for methyl acrylate in the bulk $\uparrow$}

\author{
Christopher Barner-Kowollik, *ab Sabine Beuermann, ${ }^{\mathrm{c}}$ Michael Buback, ${ }^{\mathrm{d}}$ \\ Patrice Castignolles, ${ }^{e}$ Bernadette Charleux, ${ }^{f}$ Michelle L. Coote, ${ }^{9}$ Robin A. Hutchinson, ${ }^{\text {h }}$ \\ Tanja Junkers, ${ }^{* i}$ Igor Lacík, ${ }^{j}$ Gregory T. Russell, ${ }^{k}$ Marek Stach ${ }^{j}$ and Alex M. van \\ Herk $^{\text {Im }}$
}

Propagation rate coefficient $\left(k_{\mathrm{p}}\right)$ data for radical polymerization of methyl acrylate $(\mathrm{MA})$ in the bulk are critically evaluated and a benchmark dataset is put forward by a task-group of the IUPAC Subcommittee on Modeling of Polymerization Kinetics and Processes. This dataset comprises previously published results from three laboratories as well as new data from a fourth laboratory. Not only do all these values of $k_{\mathrm{p}}$ fulfill the recommended consistency checks for reliability, they are also all in excellent agreement with each other. Data have been obtained employing the technique of pulsed-laser polymerization (PLP) coupled with molar-mass determination by size-exclusion chromatography (SEC), where PLP has been carried out at pulse-repetition rates of up to $500 \mathrm{~Hz}$, enabling reliable $k_{\mathrm{p}}$ to be obtained through to $60{ }^{\circ} \mathrm{C}$. The best-fit - and therefore recommended - Arrhenius parameters are activation energy $E_{\mathrm{A}}=17.3 \mathrm{~kJ} \mathrm{~mol}^{-1}$ and pre-exponential (frequency) factor $A=1.41 \times 10^{7} \mathrm{~L} \mathrm{~mol}^{-1} \mathrm{~s}^{-1}$. These hold for secondary-radical propagation of $M A$, and may be used to calculate effective propagation rate coefficients for MA in situations where there is a significant population of mid-chain radicals resulting from backbiting, as will be the case at technically relevant temperatures. The benchmark dataset reveals that $k_{\mathrm{p}}$ values for MA obtained using PLP in conjunction with MALDI-ToF mass spectrometry are accurate. They also confirm, through comparison with previously obtained benchmark $k_{p}$ values for $n$-butyl acrylate, methyl methacrylate and $n$-butyl methacrylate, that there seems to be identical familytype behavior in $n$-alkyl acrylates as in $n$-alkyl methacrylates. Specifically, $k_{\mathrm{p}}$ for the $n$-butyl member of each family is about $20 \%$ higher than for the corresponding methyl member, an effect that appears to be entropic in origin. Furthermore, each family is characterized by an approximately constant $E_{\mathrm{A}}$, where the value is $5 \mathrm{~kJ} \mathrm{~mol}^{-1}$ lower for acrylates.
Received 13th June 2013 Accepted 8th July 2013

DOI: $10.1039 / c 3 p y 00774$ j

www.rsc.org/polymers
${ }^{a}$ Preparative Macromolecular Chemistry, Institut für Technische Chemie und Polymerchemie, Karlsruhe Institute of Technology (KIT), Engesserstraße 18, 76131 Karlsruhe, Germany. E-mail: christopher.barner-kowollik@kit.edu

${ }^{b}$ Institut für Biologische Grenzflächen, Karlsruhe Institute of Technology (KIT), Hermann-von-Helmholtz Platz 1, 76344 Eggenstein-Leopoldshafen, Germany

'Institute of Technical Chemistry, Clausthal University of Technology, ArnoldSommerfeld-Straße 4, 38678 Clausthal-Zellerfeld, Germany

${ }^{d}$ Technical and Macromolecular Chemistry Group, Institut für Physikalische Chemie, University of Göttingen, Tammannstraße 6, D-37077 Göttingen, Germany

${ }^{e}$ University of Western Sydney, Australian Centre for Research on Separation Science (ACROSS), School of Science and Health, Parramatta Campus, Locked Bag 1797, Penrith 2751, Australia

${ }^{f}$ Université de Lyon, Univ. Lyon 1, CPE Lyon, CNRS UMR 5265, Laboratoire de Chimie Catalyse Polymères et Procédés (C2P2), Equipe LCPP Bat 308F, $43 \mathrm{Bd} d u$ 11 Novembre 1918, F-69616 Villeurbanne, France

${ }^{8}$ ARC Centre of Excellence for Free-Radical Chemistry and Biotechnology, Research School of Chemistry, Australian National University, Canberra ACT 0200, Australia
${ }^{h}$ Department of Chemical Engineering, Dupuis Hall, Queen's University, Kingston, Ontario K $7 L$ 3N6, Canada

${ }^{i}$ Polymer Reaction Design Group, Institute for Materials Research, Universiteit Hasselt, Agoralaan D, BE-3590 Diepenbeek, Belgium. E-mail: tanja.junkers@ uhasselt.be

${ }^{i}$ Department for Biomaterials Research, Polymer Institute of the Slovak Academy of Sciences, Dubravska cesta 9, 84541 Bratislava, Slovakia

${ }^{k}$ Department of Chemistry, University of Canterbury, Private Bag 4800, Christchurch 8140, New Zealand

IInstitute of Chemical and Engineering Sciences, 1 Pesek Road, Jurong Island, Singapore 627833

${ }^{m}$ Eindhoven University of Technology, Polymer Reaction Engineering, PO Box 513, $5600 \mathrm{MB}$ Eindhoven, The Netherlands

$\dagger$ Electronic supplementary information (ESI) available. See DOI: 10.1039/c3py00774j 


\section{Introduction}

The precise knowledge of rate coefficients for the individual reactions in radical polymerization is crucial for the modeling of polymerization processes and for the understanding and development of new polymerization methodologies. The fundamental reactions governing radical polymerization processes are initiation, propagation and termination, with the propagation reaction taking a prominent role, since it defines the rate of monomer consumption and thus directly affects the overall rate of polymerization. As a consequence, the propagation rate coefficient, $k_{\mathrm{p}}$, is of utmost importance, and most other rate coefficients, such as those for termination or transfer, are measured relative to it. The IUPAC Subcommittee on Modeling of Polymerization Kinetics and Processes recommended the socalled pulsed-laser polymerization-size-exclusion chromatography (PLP-SEC) technique ${ }^{1}$ as the method of choice to reliably determine $k_{\mathrm{p}}{ }^{2}$ A series of benchmark papers have reported accurate Arrhenius data for $k_{\mathrm{p}}$ of a broad range of monomers. ${ }^{2-7}$ With PLP-SEC, $k_{\mathrm{p}}$ becomes available by the correlation of the time between two consecutive laser pulses with the chain length of the generated polymeric material. This correlation is based on the almost instantaneous initiating and terminating action of each laser pulse, which gives rise to a specific molar-mass distribution (MMD) exhibiting patterns of peaks according to the darktime $t_{0}$ and multiples thereof, these reflecting the circumstance that some of the growing radicals survive one or more laser pulses and continue their growth over such an extended time period. $k_{\mathrm{p}}$ is directly accessed from eqn (1): ${ }^{8}$

$$
\mathrm{DP}_{i}=i k_{\mathrm{p}} c_{\mathrm{M}} t_{0}
$$

Here $\mathrm{DP}_{i}$ refers to characteristic degrees of polymerization outlined above, these manifesting themselves as points of inflection on the MMD, while $c_{\mathrm{M}}$ is the known monomer concentration. The accuracy of the method is limited by problems associated with molar-mass determination. In addition, side reactions such as chain transfer or very rapid radical termination may pose problems.

One family of monomers that has proven to be difficult to access via PLP-SEC is the acrylates. Undefined MMDs may occur with these monomers, as well as a dependence of the obtained (apparent) propagation rate coefficient on the pulse-repetition rate. Thus the clear correlation between $t$ and $\mathrm{DP}_{i}$ may be obscured. ${ }^{\mathbf{9}, 10}$ The importance of the transfer-to-polymer reaction in acrylate polymerizations was foreseen by Scott and Senogles. ${ }^{11-13}$ However, only after the important finding of Ahmad et $a l .{ }^{14}$ and Chiefari et al. ${ }^{15}$ the absence of a characteristic MMD structure was understood to result primarily from the formation of tertiary mid-chain radicals (MCRs). These MCRs exhibit a considerably higher stability and thus lower propagation activity than secondary chain-end radicals (see Scheme 1), thereby broadening the radical MMD and thus invalidating eqn (1). ${ }^{\mathbf{1 6}}$ Transfer-to-polymer may occur via inter- or intra-molecular reactions. ${ }^{\mathbf{1 7}}$ Intermolecular transfer only matters in terms of kinetics of polymerization at higher polymer concentrations, which do not occur in typical PLP-SEC experiments.

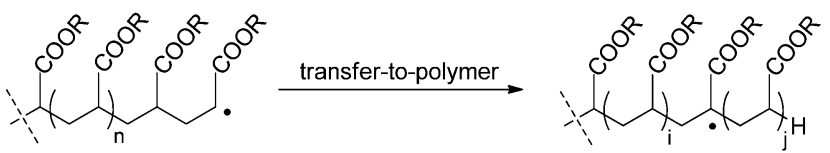

Scheme 1 Formation of mid-chain radicals by the intramolecular transfer-to-polymer reaction of secondary chain-end radicals in acrylate polymerization, where $i+j=n+1$; for the most favored backbiting process via a six-membered ring transition structure, $j=2$.

Intramolecular transfer, on the other hand, which occurs either via a random transfer step or, more frequently, via a sixmembered cyclic transition state, is an important process even at low degrees of monomer conversion. The latter reaction is referred to as backbiting. ${ }^{\mathbf{1 8 , 1 9}}$

The impact of intramolecular chain transfer on PLP was suggested $^{\mathbf{1 6}}$ and the consequences were addressed in an IUPAC benchmark paper on $k_{\mathrm{p}}$ of $n$-butyl acrylate (BA). ${ }^{6}$ Reliable $k_{\mathrm{p}}$ values of secondary BA radicals were determined at low temperatures $\left(<20^{\circ} \mathrm{C}\right)$, where laser pulsing could be applied at repetition rates that are sufficiently high to minimize the occurrence of MCR formation. As Arrhenius parameters for $k_{\mathrm{p}}$ of BA were reported, propagation rate coefficients could be extrapolated to technically relevant temperatures. It is, however, important to note that such an extrapolation yields $k_{\mathrm{p}}$ data of secondary chain-end macroradicals, whereas actual polymerizing systems at these higher temperatures contain a mixture of secondary and (much more slowly propagating) tertiary radicals. The propagation rate of secondary radicals should thus not be confused with the effective rate of propagation that applies in acrylate polymerization above low temperatures and refers to the joint action of propagating secondary and tertiary radicals., ${ }^{\mathbf{9} 20}$

Significant advances have been made in the understanding of acrylate (transfer) kinetics since the benchmark report on BA. ${ }^{6}$ Online discrimination and quantification of MCRs and secondary propagating radicals (SPRs) became available via electron paramagnetic resonance (EPR) spectroscopy. ${ }^{21-23}$ Rate coefficients for backbiting have been reported and the rate of monomer addition to BA MCRs has been studied in detail. ${ }^{\mathbf{1 0 , 2 2 , 2 3}}$ With the advent of pulse lasers with repetition rates as high as $500 \mathrm{~Hz}$, successful PLP-SEC experiments on BA were carried out up to $60{ }^{\circ} \mathrm{C}^{24}$ The resulting values are in excellent agreement with the ones extrapolated from the previously reported benchmark data determined at lower polymerization temperatures, underpinning the quality of both datasets. The results, however, also indicated another limitation, namely $\beta$-scission of the MCRs. ${ }^{25,26}$ At temperatures above $60{ }^{\circ} \mathrm{C}$, a deviation from Arrhenius behavior of the evaluated rate coefficients was observed. This could not be explained by transfer-to-polymer steps, but was attributed to $\beta$-scission of MCRs. ${ }^{24}$ This scission reaction, which is associated with a relatively high activation energy, ${ }^{27}$ yields significant amounts of unsaturated macromonomer species at temperatures above $100{ }^{\circ} \mathrm{C}$, especially during polymerizations at low radical concentrations. ${ }^{15,28}$ Each $\beta$-scission step is preceded by a transfer-to-polymer step. The scission step poses additional problems for PLP-SEC experiments, as radicals are formed that are smaller than the 
preceding MCR. However, at moderate temperatures the impact of $\beta$-scission may be neglected and, as was demonstrated for BA, $k_{\mathrm{p}}$ of SPRs may be deduced by extrapolation.

In conclusion, the understanding of acrylate kinetics has advanced significantly during recent years, and although some uncertainties still exist, propagation rate coefficients of secondary chain-end radicals may be accurately measured. The present report focuses on providing benchmark data for bulk polymerization of methyl acrylate (MA), a monomer that is of both application-oriented and academic interest.

\section{Collation of data}

Due to the inherent difficulties in the determination of reliable acrylate propagation rate coefficients, only a limited number of $k_{\mathrm{p}}$ datasets exist for MA. Earlier data from methods other than PLPSEC exhibit a large scatter and are not considered for the present evaluation. The following groups have provided the critically evaluated $k_{\mathrm{p}}$ data for bulk MA that are collated in Table 1:

\section{van Herk and co-workers (Eindhoven laboratories)}

The group of van Herk reported two datasets, one of which was measured by Manders via classical PLP-SEC at a pulse repetition rate of $100 \mathrm{~Hz}$ and temperatures from -20 to $+30{ }^{\circ} \mathrm{C}^{29}$ Bulk polymerization of MA was investigated with 2,2-dimethoxy-2phenylacetophenone (DMPA) as the photoinitiator at concentrations from 0.00045 to $0.0024 \mathrm{~mol} \mathrm{~L}^{-1}$. For analysis of molar mass distributions from SEC, the Mark-Houwink-KuhnSakurada (MHKS) values provided by Hutchinson et al. ${ }^{30} \alpha=$ 0.66 and $K=19.5 \times 10^{-5} \mathrm{dL} \mathrm{g}^{-1}$, were employed. In the more recent study of this group, molar masses of poly(MA) from PLP were analyzed by the matrix-assisted laser-desorption ionization-time of flight (MALDI-ToF) technique. The latter method, which avoids the band broadening problems of SEC, was used between -30 and $+40{ }^{\circ} \mathrm{C}$ by Willemse et al. ${ }^{31}$ with PLP repetition rates up to $100 \mathrm{~Hz}$. The advantages of MALDI-ToF over SEC for determination of $\mathrm{DP}_{i}$ and the resulting accuracy of $k_{\mathrm{p}}$ data will be addressed below.

\section{Buback and co-workers (Göttingen laboratories)}

Buback et al. investigated $k_{\mathrm{p}}$ of MA under high-pressure conditions between -15 and $-28{ }^{\circ} \mathrm{C}$ with DMPA as the photoinitiator. ${ }^{32}$ Consistent $k_{\mathrm{p}}$ data adhering to the criteria for reliable $k_{\mathrm{p}}$ determination were obtained. The pressure dependence of $k_{\mathrm{p}}$ is associated with an activation volume of $(11.7 \pm 0.4) \mathrm{cm}^{3} \mathrm{~mol}^{-1}$ at $-28{ }^{\circ} \mathrm{C}$ and $(11.2 \pm 0.7) \mathrm{cm}^{3} \mathrm{~mol}^{-1}$ at $-15^{\circ} \mathrm{C}$. Extrapolation of the $k_{\mathrm{p}}$ data to ambient pressure yields $3360 \mathrm{~L} \mathrm{~mol}^{-1} \mathrm{~s}^{-1}$ for $-28{ }^{\circ} \mathrm{C}$ and $5270 \mathrm{~L} \mathrm{~mol}^{-1} \mathrm{~s}^{-1}$ for $-15^{\circ} \mathrm{C}$. The MHKS parameters provided by Hutchinson et al. ${ }^{30}$ were used for SEC analysis.

\section{Barner-Kowollik, Junkers, Castignolles and co-workers} (Karlsruhe laboratories)

Junkers et al. ${ }^{33}$ provided data from DMPA-initiated PLP-SEC of MA in the range from 11.3 to $81.2{ }^{\circ} \mathrm{C}$. To successfully carry out measurements up to the highest temperatures, fast pulsing with a $500 \mathrm{~Hz}$ laser was applied in order to largely eliminate the influence of backbiting on the resulting molar mass distributions. Excellent repeatability of MMDs, including higher-order inflection points, was observed at all temperatures. In order to stay on the safe side, Junkers et al. ${ }^{33}$ used only the restricted temperature range up to $60{ }^{\circ} \mathrm{C}$ for deriving Arrhenius parameters of $k_{\mathrm{p}}$. Above $60{ }^{\circ} \mathrm{C}$, a leveling-off of $k_{\mathrm{p}}$ was seen and was attributed to the influence of $\beta$-scission on the polymer $\mathrm{MMD},{ }^{15,25}$ an effect that would lead to underestimation of $k_{\mathrm{p}}$ due to an increased polymer background in the sample stemming from the scission fragments. ${ }^{9,10}$ MHKS parameters for a broad temperature range using PLP-generated poly(MA) samples were determined to be: $\alpha=0.74$ and $K=10.2 \times 10^{-5} \mathrm{dL} \mathrm{g}^{-1}$ (THF, 30 ${ }^{\circ} \mathrm{C}$ ). Additionally, all samples were assessed with respect to the error margins associated with size-exclusion chromatography and to the local dispersity profile resulting from multiple detection analysis of branched polymer. Relatively homogeneous branching distributions were observed, confirming that SEC can indeed be used with high accuracy for determination of MMDs of poly(MA), as was also found for BA. However, this finding must not necessarily hold true for other acrylates, such as 2-ethylhexyl acrylate ${ }^{34}$ or tert-butyl acrylate. ${ }^{35}$

\section{Stach and Lacik (Bratislava laboratories)}

In the framework of the current $k_{\mathrm{p}}$ collation, a new dataset for bulk MA polymerization has been compiled by Stach and Lacík, also using high pulse repetition rates of 250 and $500 \mathrm{~Hz}$. Temperatures from -26 to $+80{ }^{\circ} \mathrm{C}$ were covered (see the $\mathrm{ESI} \dagger$ for experimental details) with $0.0005,0.005$ and $0.020 \mathrm{~mol} \mathrm{~L}^{-1}$ DMPA as the photoinitiator. The same MHKS parameters as in the study of Junkers et al. ${ }^{33}$ were used for SEC analysis. Also in this study a leveling-off of $k_{\mathrm{p}}$ data was observed at temperatures above $60^{\circ} \mathrm{C}$, although points of inflection for both $i=1$ and 2 in eqn (1) could be seen even at $70{ }^{\circ} \mathrm{C}$. In addition to producing polymer by a single sequence of laser pulses applied at high repetition rate, in a second type of experiment polymer samples were made by applying several sequences of laser pulses with a reduced number of pulses per sequence. With this second approach, the reaction mixture can equilibrate back to the thermostat temperature during an experiment, meaning that any enhancement of temperature as a consequence of rapid pulsing (and hence rapid polymerization) should become visible from comparison of $k_{\mathrm{p}}$ values obtained by the two pulsing strategies. It is gratifying to note that no significant difference in $k_{\mathrm{p}}$ has been found upon applying the two pulsing procedures (see Table 1 for the comparison).

\section{Deriving benchmark values}

The $k_{\mathrm{p}}$ datasets in Table 1 were estimated using slightly different monomer densities (for the calculation of bulk monomer concentration). In addition, different MHKS parameters were applied for SEC analysis depending on the type and temperature of the eluent. The associated error is small compared with the limits of accuracy of size-exclusion chromatographic analysis. Thus, as within the previous benchmark report on $\mathrm{BA}$, no recalculation of $k_{\mathrm{p}}$ data has been performed. 
Table 1 Critically evaluated values of propagation rate coefficient, $k_{\mathrm{p}}$, for bulk methyl acrylate polymerization at ambient pressure measured as a function of temperature, $\theta$, laser pulse repetition rate, $f$, average laser-pulse energy, $E_{\mathrm{p}}$, and initiator concentration, $C_{1}$. Values of $k_{\mathrm{p}}$ for $T$ $>60{ }^{\circ} \mathrm{C}$ were not used for deducing Arrhenius parameters and are given only in the ESI $\uparrow$

\begin{tabular}{|c|c|c|c|c|c|}
\hline$\theta /{ }^{\circ} \mathrm{C}$ & $f / \mathrm{Hz}$ & $E_{\mathrm{p}} / \mathrm{mJ}$ & $c_{\mathrm{I}} / \mathrm{mmol} \mathrm{L}^{-1}$ & $k_{\mathrm{p}} / \mathrm{L} \mathrm{mol}^{-1} \cdot \mathrm{s}^{-1}$ & Ref. \\
\hline-28 & 100 & 4 & 5 & 3300 & 32 \\
\hline-26.4 & 250 & 3.0 & 0.5 & 2992 & This work \\
\hline-25.8 & 250 & 3.0 & 5 & 3166 & This work \\
\hline-25.5 & 250 & 3.0 & 5 & 3359 & This work \\
\hline-25 & 60 & 60 & 5 & 3290 & $31^{a}$ \\
\hline-25 & 60 & 40 & 5 & 3321 & $31^{a}$ \\
\hline-25 & 500 & 3.0 & 5 & 3378 & This work \\
\hline-24.6 & 250 & 3.0 & 20 & 3684 & This work \\
\hline-24.2 & 500 & 3.0 & 20 & 3553 & This work \\
\hline-19.3 & 100 & 25 & 5.3 & 3790 & 29 \\
\hline-19.1 & 100 & 25 & 5.3 & 3740 & 29 \\
\hline-18.5 & 100 & 25 & 5.3 & 3680 & 29 \\
\hline-17.9 & 100 & 25 & 5.3 & 3860 & 29 \\
\hline-17.5 & 100 & 25 & 5.3 & 3920 & 29 \\
\hline-17.1 & 100 & 25 & 5.3 & 3870 & 29 \\
\hline-16.6 & 100 & 25 & 5.3 & 3930 & 29 \\
\hline-16.3 & 100 & 25 & 5.3 & 4060 & 29 \\
\hline-16.2 & 100 & 25 & 5.3 & 4120 & 29 \\
\hline-16.0 & 100 & 25 & 5.3 & 3930 & 29 \\
\hline-15.8 & 500 & 3.0 & 5 & 4135 & This work $^{b}$ \\
\hline-15.7 & 80 & 60 & 5.00 & 4643 & $31^{a}$ \\
\hline-15.6 & 80 & 40 & 5.00 & 4567 & $31^{a}$ \\
\hline-15 & 100 & 4 & 5.00 & 5300 & 32 \\
\hline-11.3 & 100 & 25 & 1.1 & 5410 & 29 \\
\hline-11.3 & 100 & 25 & 1.1 & 5370 & 29 \\
\hline-11.3 & 100 & 25 & 1.1 & 5290 & 29 \\
\hline-11.3 & 80 & 25 & 1.1 & 5060 & 29 \\
\hline-11.3 & 100 & 25 & 2.4 & 5240 & 29 \\
\hline-11.3 & 100 & 25 & 2.4 & 5200 & 29 \\
\hline-11.3 & 100 & 25 & 2.4 & 5340 & 29 \\
\hline-8 & 100 & 60 & 5.00 & 5788 & $31^{a}$ \\
\hline-8 & 100 & 40 & 5.00 & 5797 & $31^{a}$ \\
\hline-2.9 & 100 & 25 & 2.4 & 6560 & 29 \\
\hline-2.7 & 100 & 25 & 1.1 & 6600 & 29 \\
\hline-2.7 & 100 & 25 & 2.4 & 6540 & 29 \\
\hline-2.5 & 100 & 25 & 1.1 & 6680 & 29 \\
\hline-1.9 & 100 & 25 & 1.1 & 6790 & 29 \\
\hline-0.5 & 100 & 25 & 2.4 & 6790 & 29 \\
\hline-0.3 & 80 & 25 & 1.1 & 6170 & 29 \\
\hline 0 & 250 & 3.0 & 5 & 7031 & This work \\
\hline 0 & 250 & 3.0 & 5 & 7198 & This work \\
\hline 0 & 500 & 3.0 & 5 & 7655 & This work \\
\hline 0 & 500 & 3.0 & 5 & 7421 & This work \\
\hline 0 & 250 & 3.0 & 20 & 7523 & This work \\
\hline 0 & 250 & 3.0 & 20 & 7322 & This work \\
\hline 0 & 500 & 3.0 & 20 & 7286 & This work \\
\hline 0 & 500 & 3.0 & 20 & 7725 & This work \\
\hline 0.1 & 500 & 3.0 & 5 & 7325 & This work $^{b}$ \\
\hline 0.9 & 100 & 60 & 5.00 & 7593 & $31^{a}$ \\
\hline 0.9 & 100 & 40 & 5.00 & 7619 & $31^{a}$ \\
\hline 1.9 & 100 & 20 & 1.2 & 6170 & 29 \\
\hline 2.2 & 100 & 20 & 1.2 & 6370 & 29 \\
\hline 3.8 & 100 & 25 & 1.0 & 6130 & 29 \\
\hline 3.8 & 100 & 25 & 1.0 & 6740 & 29 \\
\hline 4.0 & 100 & 25 & 1.0 & 6530 & 29 \\
\hline 4.2 & 100 & 20 & 1.2 & 5990 & 29 \\
\hline 7.8 & 100 & 60 & 5.00 & 9308 & $31^{a}$ \\
\hline 7.8 & 100 & 40 & 5.00 & 9299 & $31^{a}$ \\
\hline
\end{tabular}

Table 1 (Contd.)

\begin{tabular}{|c|c|c|c|c|c|}
\hline$\theta /{ }^{\circ} \mathrm{C}$ & $f / \mathrm{Hz}$ & $E_{\mathrm{p}} / \mathrm{mJ}$ & $c_{\mathrm{I}} / \mathrm{mmol} \mathrm{L}^{-1}$ & $k_{\mathrm{p}} / \mathrm{L} \mathrm{mol}{ }^{-1} \cdot \mathrm{s}^{-1}$ & Ref. \\
\hline 11.3 & 500 & 1.5 & 5.00 & 9401 & 33 \\
\hline 11.9 & 500 & 1.5 & 5.00 & 10320 & 33 \\
\hline 12.4 & 100 & 25 & 1.1 & 9740 & 29 \\
\hline 15 & 100 & 30 & 5.00 & 11397 & $31^{a}$ \\
\hline 15 & 100 & 15 & 5.00 & 11397 & $31^{a}$ \\
\hline 19.8 & 500 & 1.5 & 5.00 & 13011 & 33 \\
\hline 19.8 & 500 & 3.0 & 5 & 11578 & This work $^{b}$ \\
\hline 20 & 250 & 3.0 & 0.5 & 10892 & This work \\
\hline 20 & 500 & 3.0 & 0.5 & 11812 & This work \\
\hline 20 & 250 & 3.0 & 5 & 10850 & This work \\
\hline 20 & 250 & 3.0 & 5 & 11054 & This work \\
\hline 20 & 500 & 3.0 & 5 & 11842 & This work \\
\hline 20 & 500 & 3.0 & 5 & 12046 & This work \\
\hline 20 & 250 & 3.0 & 20 & 10924 & This work \\
\hline 20 & 250 & 3.0 & 20 & 11004 & This work \\
\hline 20 & 500 & 3.0 & 20 & 11792 & This work \\
\hline 20 & 500 & 3.0 & 20 & 12101 & This work \\
\hline 20.4 & 500 & 1.5 & 5.00 & 12826 & 33 \\
\hline 21.8 & 100 & 30 & 5.00 & 13727 & $31^{a}$ \\
\hline 22.3 & 100 & 15 & 5.00 & 13808 & $31^{a}$ \\
\hline 25.0 & 100 & 20 & 0.45 & 14600 & 29 \\
\hline 25.0 & 100 & 20 & 0.45 & 13800 & 29 \\
\hline 25.0 & 100 & 20 & 0.45 & 14000 & 29 \\
\hline 25.0 & 100 & 10 & 0.45 & 14000 & 29 \\
\hline 25.0 & 100 & 10 & 0.45 & 13500 & 29 \\
\hline 25.0 & 100 & 10 & 0.45 & 14000 & 29 \\
\hline 25.0 & 80 & 20 & 0.45 & 13400 & 29 \\
\hline 25.0 & 80 & 20 & 0.45 & 12900 & 29 \\
\hline 29.7 & 500 & 1.5 & 5.00 & 15851 & 33 \\
\hline 29.8 & 100 & 30 & 5.00 & 16461 & $31^{a}$ \\
\hline 29.9 & 100 & 30 & 5.00 & 16317 & $31^{a}$ \\
\hline 30.8 & 500 & 1.5 & 5.00 & 13944 & 33 \\
\hline 32.0 & 100 & 2 & 1.2 & 15100 & 29 \\
\hline 32.0 & 100 & 2 & 1.2 & 14700 & 29 \\
\hline 35.7 & 500 & 3.0 & 5 & 16796 & This work ${ }^{b}$ \\
\hline 36.5 & 100 & 30 & 5.00 & 19376 & $31^{a}$ \\
\hline 37.2 & 100 & 15 & 5.00 & 19578 & $31^{a}$ \\
\hline 40 & 500 & 3.0 & 0.5 & 17756 & This work \\
\hline 40 & 500 & 3.0 & 5 & 17419 & This work \\
\hline 40 & 500 & 3.0 & 5 & 17379 & This work \\
\hline 40 & 500 & 3.0 & 20 & 17244 & This work \\
\hline 40 & 500 & 3.0 & 20 & 17499 & This work \\
\hline 40 & 500 & 3.0 & 5 & 17900 & This work \\
\hline 40 & 500 & 3.0 & 5 & 18151 & This work \\
\hline 40.3 & 500 & 1.5 & 5.00 & 21079 & 33 \\
\hline 40.3 & 500 & 1.5 & 5.00 & 21480 & 33 \\
\hline 50.2 & 500 & 1.5 & 5.00 & 26041 & 33 \\
\hline 50.4 & 500 & 1.5 & 5.00 & 26297 & 33 \\
\hline 60 & 500 & 3.0 & 20 & 24211 & This work \\
\hline 60 & 500 & 3.0 & 20 & 23930 & This work \\
\hline 60 & 500 & 3.0 & 5 & 25019 & This work \\
\hline 60 & 500 & 3.0 & 5 & 25740 & This work \\
\hline 60.5 & 500 & 1.5 & 5.00 & 31654 & 33 \\
\hline 60.6 & 500 & 1.5 & 5.00 & 31965 & 33 \\
\hline
\end{tabular}

${ }^{a}$ Characteristic MMDs were determined via MALDI-ToF rather than by SEC. ${ }^{b}$ PLP experiments performed with interrupted sequences of laser pulses (see text).

The $k_{\mathrm{p}}$ data in Table 1 refer to different temperatures, laser repetition rates, $f$, average laser pulse energies, $E_{\mathrm{p}}$, and initiator concentrations, $c_{\mathrm{I}}$. All data were obtained using the 


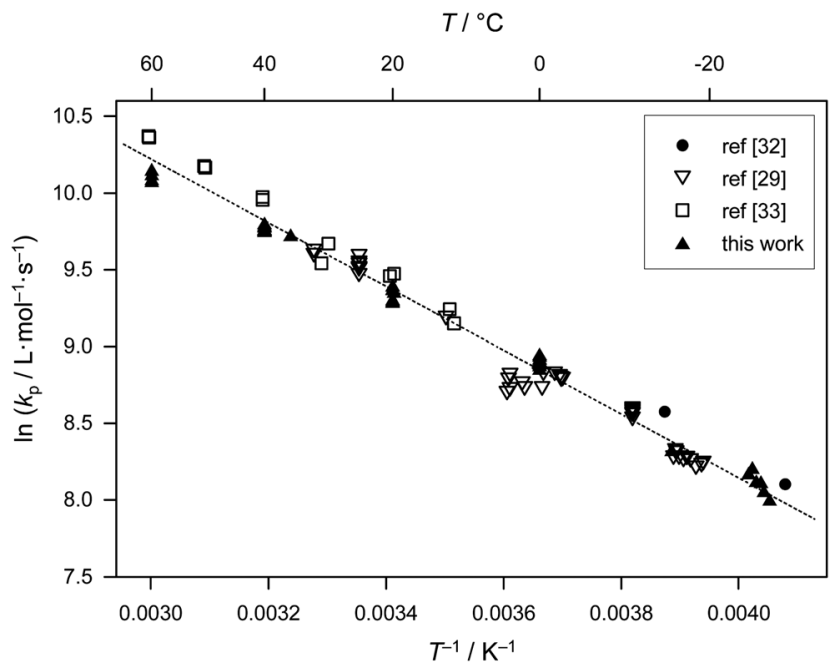

Fig. 1 Arrhenius plot of values of propagation rate coefficient, $k_{\mathrm{p}}$, for bulk methyl acrylate from Table 1. Eqn (2), the best-fit line to all the points, is also shown.

photoinitiator DMPA, which has proven to be an excellent choice for acrylate PLP-SEC experiments. In fulfillment of the IUPAC reliability criteria, ${ }^{2}$ close matching of data obtained at different laser pulse energies is observed. Consistent $k_{\mathrm{p}}$ values are thus derived upon variation of initial radical concentrations. The combined datasets display good agreement and exhibit very satisfactory Arrhenius-type behavior, as depicted in Fig. 1. The scatter of the $k_{\mathrm{p}}$ data provided by the different groups is relatively small and well within the general error margin of 20 per cent that is associated with PLP-SEC measurements.

The unweighted Arrhenius fit of the $k_{\mathrm{p}}$ data in Fig. 1 is given as:

$$
\ln \left(k_{\mathrm{p}} / \mathrm{L} \mathrm{mol}{ }^{-1} \mathrm{~s}^{-1}\right)=16.46( \pm 0.11)-2080( \pm 30) K / T
$$

where $T$ is the absolute temperature.

Eqn (2) gives activation energy $E_{\mathrm{A}}=17.29 \mathrm{~kJ} \mathrm{~mol}^{-1}$ and frequency (pre-exponential) factor $A=1.41 \times 10^{7} \mathrm{~L} \mathrm{~mol}^{-1} \mathrm{~s}^{-1}$. The error margins of both Arrhenius parameters are represented via the $95 \%$ confidence interval in Fig. 2 . The estimate is made on the assumption of a constant relative error of $20 \%$ for each individual $k_{\mathrm{p}}$ value. The resulting uncertainties amount to 16.3 $\mathrm{kJ} \mathrm{mol}^{-1}<E_{\mathrm{A}}<18.2 \mathrm{~kJ} \mathrm{~mol}^{-1}$ and $0.9 \times 10^{7} \mathrm{~L} \mathrm{~mol}^{-1} \mathrm{~s}^{-1}<A<2.0$ $\times 10^{7} \mathrm{~L} \mathrm{~mol}^{-1} \mathrm{~s}^{-1}$. These error margins are very close to the ones of the benchmark $k_{\mathrm{p}}$ dataset for $\mathrm{BA}^{6}{ }^{6}$ The error limitations obtained from the joint confidence interval mostly depend on the scatter of the data, whereas trying different relative errors of 10,15 and $20 \%$ in $k_{\mathrm{p}}$ yielded very similar contour plots.

The $k_{\mathrm{p}}$ data of Willemse and van Herk in Table 1 play a special role, as these values were determined via MALDI-ToF analysis of MMDs, and thus should not suffer from the SEC problems of imperfect calibration and band broadening. On the other hand, features in the measured number distributions may not always be unambiguously identified. Additional uncertainties exist with regard to the question of whether the distribution from MALDI-ToF reflects the true distribution, as mass spectrometry is inherently prone to mass discrimination effects,

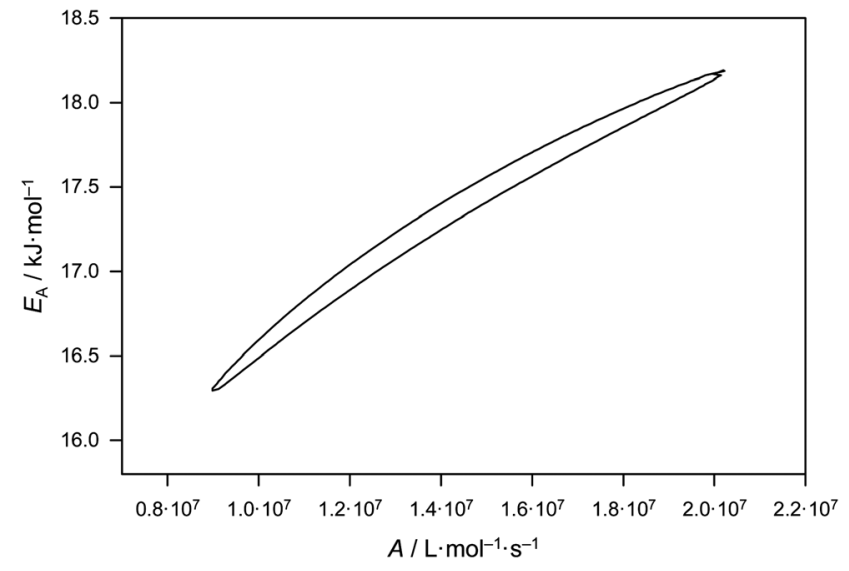

Fig. $295 \%$ joint-confidence interval for the Arrhenius parameters for $k_{\mathrm{p}}$ of bulk MA, as estimated from fitting of the data in Fig. 1 (see text).

especially for higher molar masses and broad distributions, ${ }^{36}$ as occur in PLP experiments. It is gratifying to note that, irrespective of these limitations of PLP-MALDI-ToF, very pleasing agreement of the data from the two methods of molar mass analysis is seen: plotting the PLP-SEC data together with the PLP-MALDI-ToF data yields excellent agreement of the $k_{\mathrm{p}}$ values deduced from the two PLP-based methods (Fig. 3), with the Arrhenius parameters being more or less identical. One remark can be made at this point; because band broadening in SEC systematically underestimates the $k_{\mathrm{p}}$-values (taking the lowmolecular weight inflection point, this point is shifted to lower values due to band broadening) the MALDI-ToF data are systematically slightly higher than the SEC data, as observed in Fig. 3. These statements do not, however, prove the general applicability of the PLP-MALDI-ToF method. Nevertheless, the close agreement hints at the good applicability of the MALDI-

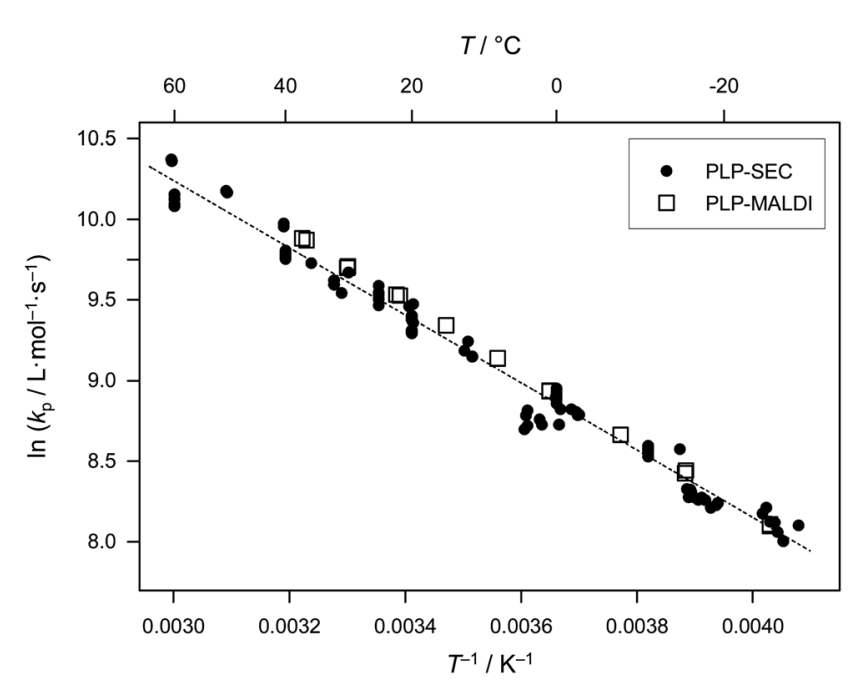

Fig. 3 Comparison of literature $k_{\mathrm{p}}$ data for bulk MA obtained via PLPSEC (data from Fig. 1, full circles) and PLP-MALDI-ToF (data from Willemse et al., ${ }^{31}$ open squares); the dashed line represents the Arrhenius fit (equation not given) to the combined dataset, i.e., from both PLP-based methods. 
ToF approach. This notwithstanding, and in order to follow the IUPAC suggestion of using PLP-SEC for reliable $k_{\mathrm{p}}$ determination, the values provided by Willemse et al. were not included in the joint fit shown in Fig. 1.

\section{Discussion}

Benchmark data are of more than just empirical use. For example, they may serve to definitively elucidate mechanistic trends, and also to establish the utility of predictive calculation methodologies.

\section{Comparison with quantum-chemical calculations}

With increasing computational power and ongoing refinement of models, it seems worthwhile to compare the experimental benchmark data with results from quantum-chemical (QM) calculations, as were performed for $k_{\mathrm{p}}$ of bulk MA by Coote and co-workers. ${ }^{37}$ Using the G3(MP2)-RAD methodology for calculation of gas-phase rate coefficients and accounting for solvation effects by applying the COSMO-RS model, an activation energy of $21.8 \mathrm{~kJ} \mathrm{~mol}^{-1}$ and a frequency factor of $A=3.2 \times 10^{7} \mathrm{~L} \mathrm{~mol}^{-1} \mathrm{~s}^{-1}$ were obtained for the addition of a dimer radical to the monomer in bulk monomer solution. The absolute $k_{\mathrm{p}}$ at $20^{\circ} \mathrm{C}$ calculated from these parameters underestimates the value from the benchmark dataset (eqn (2)) by a factor of 2.8. The agreement of the quantum-chemically estimated $k_{\mathrm{p}}$ and Arrhenius parameters to better than one order of magnitude of the experimental benchmark values indicates the improvements made with such computational methods in recent times. Nevertheless, the approximations required for the QM calculations do not yet allow for $a b$ initio calculations of benchmark $k_{\mathrm{p}}$ values. $^{38}$

\section{Comparison with benchmark $k_{\mathrm{p}}$ data for other monomers}

Benchmark $k_{\mathrm{p}}$ values for a series of methacrylate monomers as well as for BA have previously been published..$^{2-7}$ Largely based on the more extensive results for methacrylate monomers, a family-type behavior was proposed, this being that within a family of monomers, $k_{\mathrm{p}}$ shows a minor but systematic increase with the size of the alkyl ester group due largely, perhaps entirely, to $A$ variation. The observed trends may help to predict $k_{\mathrm{p}}$ values of family members which have been less thoroughly studied. The comparison of benchmark values for bulk BA and bulk MA with the corresponding values for $n$-butyl methacrylate (BMA) and methyl methacrylate (MMA) is illustrated in Fig. 4.

Fig. 4 undoubtedly represents a very significant achievement of experimental science in the way it neatly establishes both family behavior and at the same time the differences between families: the methyl and $n$-butyl members of each family are close to each other while the differences between families are distinct. The activation energies of MMA and BMA differ by only $0.5 \mathrm{~kJ} \mathrm{~mol}^{-1}$ and the frequency factor only by about $40 \%$, which poses problems toward safely establishing whether one or the other or both Arrhenius parameters are different. On the other hand, it is clearly established that bulk $k_{\mathrm{p}}$ of BMA is above the associated value for MMA, e.g., for $20{ }^{\circ} \mathrm{C}$ the numbers are $272 \mathrm{~L}$ $\mathrm{mol}^{-1} \mathrm{~s}^{-1}$ (MMA) and $314 \mathrm{~L} \mathrm{~mol}^{-1} \mathrm{~s}^{-1}$ (BMA). The ratio of these

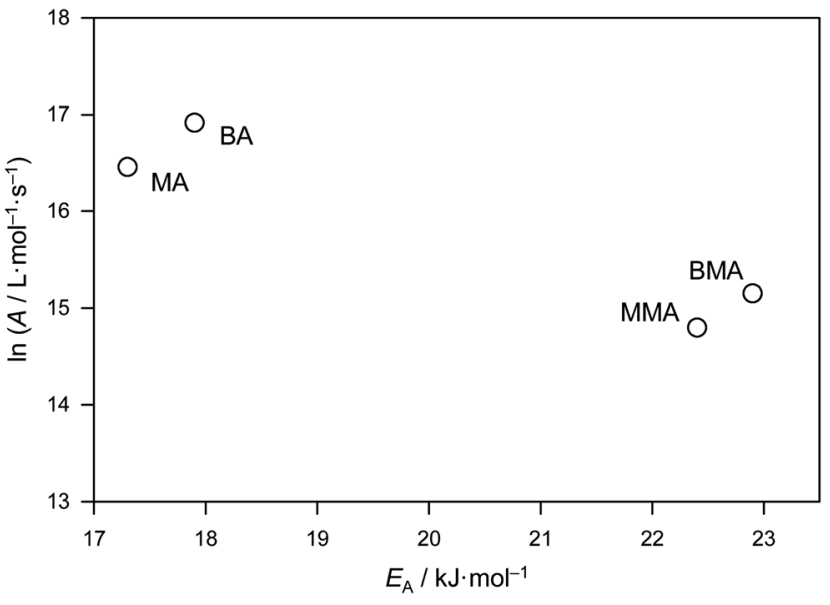

Fig. 4 Arrhenius parameters for the benchmark propagation rate coefficients of bulk methyl acrylate (MA), $n$-butyl acrylate (BA), methyl methacrylate (MMA) and $n$-butyl methacrylate (BMA).5,6

values, $k_{\mathrm{p}}(\mathrm{MMA}) / k_{\mathrm{p}}(\mathrm{BMA})$, is 0.87 . The benchmark data for MA enable a similar comparison for MA and BA. Both acrylates exhibit lower activation energies than the corresponding methacrylates, but differ marginally from each other, i.e., by 0.6 $\mathrm{kJ} \mathrm{mol}^{-1}$, which is within the limits of experimental accuracy. The frequency factors for bulk BA and MA are also close to each other. Again, the $n$-butyl member exhibits higher $k_{\mathrm{p}}$ than the methyl member of the same family, e.g. at $20{ }^{\circ} \mathrm{C}$ it is found that $k_{\mathrm{p}}(\mathrm{MA}) / k_{\mathrm{p}}(\mathrm{BA})=0.81$. The systematic effect of ester chain length on $k_{\mathrm{p}}$ of bulk (meth)acrylic esters is a genuine kinetic one, as is explained in more detail elsewhere. ${ }^{39}$ Also pointed out in ref. 39 is the fact that the increase of $k_{\mathrm{p}}$ with the size of the ester group, which is seen with bulk radical polymerization of alkyl acrylates and alkyl methacrylates, may not occur in solution polymerization or may even be inverted, e.g., in toluene solution, as might be seen from the data provided by Couvreur et al., ${ }^{\mathbf{4 0}}$ although the accuracy of the $k_{\mathrm{p}}$ is not established in this latter case due to multiple-detection SEC not having been available to use. Theoretical studies of MA polymerization indicate that intramolecular hydrogen bonding plays a greater role in low polarity environments compared with bulk monomer, ${ }^{37}$ and this may provide an explanation for the differing behavior.

Future activities of our IUPAC Subcommittee will focus on the quantitative analysis of the effects of substituents and molecular environment on $k_{\mathrm{p}}{ }^{41}$ These effects are basically related to the extent of internal rotational freedom of the transition state for propagation, as was first pointed out by Heuts et al. ${ }^{42}$ Significant hindrance to such internal rotational motion is associated with a lower pre-exponential factor and thus with lower $k_{\mathrm{p}}$, which effect also explains the large difference between acrylate and methacrylate $k_{\mathrm{p}}$ (although this is also due to the difference in $\left.E_{\mathrm{A}}\right)$. As compared with acrylates, methacrylates suffer from severe hindrance to rotational mobility because of the $\alpha$-methyl groups present on the polymer backbone.

Given the above-mentioned kinetic argument, which is a purely entropic one, the BA and MA $k_{\mathrm{p}}$ data are fitted in Fig. 5 assuming identical $E_{\mathrm{A}}$, viz. $17.6 \mathrm{~kJ} \mathrm{~mol}^{-1}$, the arithmetic mean 


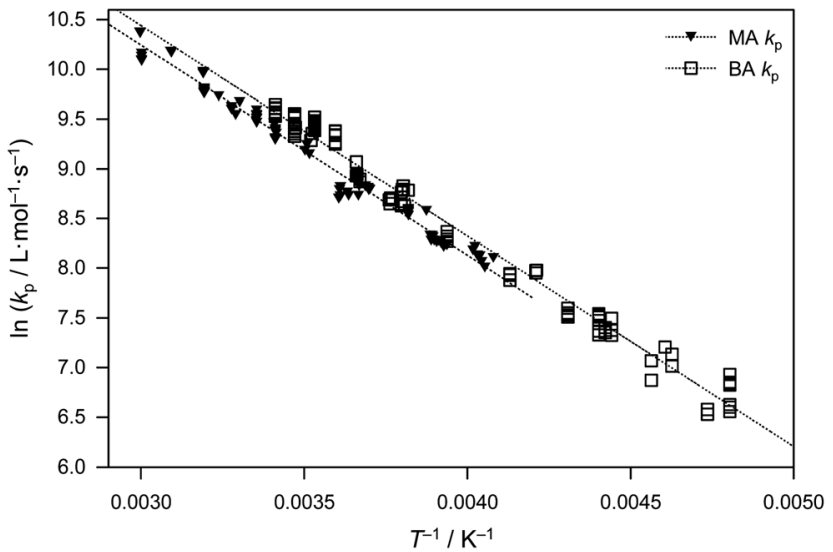

Fig. 5 Arrhenius plot comparing benchmark $k_{\mathrm{p}}$ data for methyl acrylate (present work) and $n$-butyl acrylate, ${ }^{6}$ where each dataset has been fitted using $E_{\mathrm{A}}=17.6 \mathrm{~kJ} \mathrm{~mol}^{-1}$ (see text).

Table 2 Benchmark Arrhenius parameters and $20^{\circ} \mathrm{C}$ values for bulk $k_{\mathrm{p}}$ of the methyl and butyl esters of acrylic and methacrylic acid

\begin{tabular}{|c|c|c|c|c|}
\hline Monomer & $A / \mathrm{L} \mathrm{mol}^{-1} \mathrm{~s}^{-1}$ & $\begin{array}{l}E_{\mathrm{A}} / \\
\mathrm{kJ} \mathrm{mol}^{-1}\end{array}$ & $\begin{array}{l}k_{\mathrm{p}}\left(20^{\circ} \mathrm{C}\right) / \\
\mathrm{L} \mathrm{mol}{ }^{-1} \mathrm{~s}^{-1}\end{array}$ & Ref. \\
\hline $\begin{array}{l}\text { Methyl } \\
\text { methacrylate }\end{array}$ & $2.67 \times 10^{6}$ & 22.4 & 270 & 3 \\
\hline $\begin{array}{l}n \text {-Butyl } \\
\text { methacrylate }\end{array}$ & $3.78 \times 10^{6}$ & 22.9 & 310 & 4 \\
\hline Methyl acrylate & $1.41 \times 10^{7}$ & 17.3 & 11660 & $\begin{array}{l}\text { This } \\
\text { work }\end{array}$ \\
\hline$n$-Butyl acrylate & $2.24 \times 10^{7}$ & 17.9 & 14480 & 6 \\
\hline
\end{tabular}

of the BA value from ref. $6\left(17.9 \mathrm{~kJ} \mathrm{~mol}^{-1}\right)$ and the present MA value $\left(17.3 \mathrm{~kJ} \mathrm{~mol}^{-1}\right)$. This yielded frequency factors of $A(\mathrm{MA})=$ $1.6 \times 10^{7} \mathrm{~L} \mathrm{~mol}^{-1} \mathrm{~s}^{-1}$ and $A(\mathrm{BA})=2.0 \times 10^{7} \mathrm{~L} \mathrm{~mol}^{-1} \mathrm{~s}^{-1}$, i.e., a difference of $20 \%$. Certainly to the naked eye it would seem that this fitting approach is perfectly adequate, and therefore the value $E_{\mathrm{A}}=17.6 \mathrm{~kJ} \mathrm{~mol}^{-1}$ may be cautiously recommended for secondary-radical propagation of all $n$-alkyl acrylates, with $A$ varying along the indicated lines between family members.

The increase of $k_{\mathrm{p}}$ with alkyl ester chain length is illustrated by the numbers in Table 2 for both acrylates and methacrylates. The higher degree of rotational freedom of the transition-state structure for the butyl esters is understood as being a consequence of the more efficient shielding of dipolar interactions by the larger side chain, perhaps associated with some better internal solubilizing effect of butyl as compared to methyl moieties. Variations of $k_{\mathrm{p}}$ with solvent environment have been explained via this kind of argument. ${ }^{43,44}$

\section{Effective propagation rate coefficient}

As mentioned above, under typical conditions of acrylate radical polymerization, both secondary chain-end and tertiary midchain radicals occur. It cannot be overemphasized that the benchmark $k_{\mathrm{p}}$ values reported in the present study entirely refer only to propagation of the secondary radicals. Monomer addition to mid-chain radicals takes place with a much lower rate coefficient, $k_{\mathrm{p}}^{\text {tert }}$. The major effect of mid-chain radicals on the overall propagation rate thus results from the loss of secondary radicals due to their transformation into mid-chain radicals. To account for the presence of two types of radicals, an effective propagation rate coefficient $k_{\mathrm{p}}^{\text {eff }}$ has to be defined, and can be shown to be given by $y^{6,9,20}$

$$
k_{\mathrm{p}}^{\text {eff }}=\frac{k_{\mathrm{p}}}{1+\frac{k_{\mathrm{bb}}}{k_{\mathrm{p}}^{\text {tert }} c_{\mathrm{M}}}}
$$

where $k_{\mathrm{p}}$ is the propagation rate coefficient of secondary radicals (e.g. the values reported here), $k_{\mathrm{bb}}$ refers to the rate coefficient of backbiting (see Scheme 1) and $c_{\mathrm{M}}$ is the monomer concentration. For MA, reliable values of $k_{\mathrm{p}}^{\text {tert }}$ and $k_{\mathrm{bb}}$ are not yet available, whereas such data do exist for BA. ${ }^{9,10,23,45}$ Based on the observation that under PLP conditions almost identical amounts of MCRs are observed for MA and BA polymerizations at the same temperature, ${ }^{46}$ it may be assumed that $k_{\mathrm{bb}}$ is similar for both monomers, e.g., it is close to $10^{2} \mathrm{~s}^{-1}$ at $60^{\circ} \mathrm{C}$. On the basis of existing data for BA as well as from homopropagation rates of the MA-dimer and MA trimer ${ }^{27}$ which may serve as a model for MCR propagation, $k_{\mathrm{p}}^{\text {tert }}$ can be estimated by the approximation $k_{\mathrm{p}}^{\text {tert }}=k_{\mathrm{p}} / 1000$. Both $k_{\mathrm{p}}^{\text {tert }}$ and $k_{\mathrm{bb}}$ should be precisely determined for MA within forthcoming studies. However, even without accurately knowing these parameters, the current approximate knowledge allows for an adequate estimate of the effective propagation rate coefficient of MA bulk polymerization. The resulting value for $60{ }^{\circ} \mathrm{C}$ is $8200 \mathrm{~L} \mathrm{~mol}^{-1} \mathrm{~s}^{-1}$, which is about one third of the benchmark value, according to eqn (2), for secondary propagating radicals at the same temperature.

\section{Conclusions}

Benchmark data have been collected and analyzed for the chain-growth kinetics of bulk MA secondary propagating radicals at temperatures from -28 to $61{ }^{\circ} \mathrm{C}$. The availability of commercial pulse lasers with pulse repetition rates as high as $500 \mathrm{~Hz}$ allows for PLP-SEC studies up to temperatures as high as shown here, for the unfavorable effect of backbiting is largely eliminated by not allowing sufficient time between pulses for it to occur to any significant extent. However, at the highest temperatures the impact of $\beta$-scission reactions on the MMD of PLP-structured poly(MA) must be carefully considered. The $k_{\mathrm{p}}$ values from PLP-SEC and from PLP-MALDI-ToF are in good agreement, which suggests that the latter technique may also be suitable for reliable $k_{\mathrm{p}}$ determination.

The Arrhenius pre-exponential factor and activation energy of secondary propagating MA radicals were obtained by fitting of the benchmark dataset to be $A=1.41 \times 10^{7} \mathrm{~L} \mathrm{~mol}^{-1} \mathrm{~s}^{-1}$ and $E_{\mathrm{A}}=17.3 \mathrm{~kJ} \mathrm{~mol}^{-1}$ respectively. These numbers are close to the associated ones of $n$-butyl acrylate (BA). At $20{ }^{\circ} \mathrm{C}$, bulk BA propagates faster than bulk MA by $24 \%$, which difference is close to the one seen between BMA and MMA. Thus, family type behavior of alkyl (meth)acrylate $k_{\mathrm{p}}$ is confirmed.

Overall propagation of acrylates may be estimated via effective propagation rate coefficients which, in addition to $k_{\mathrm{p}}$, 
requires accurate knowledge of $k_{\mathrm{p}}^{\text {tert }} / k_{\mathrm{bb}}$. So far, the latter two rate coefficients have been determined only for BA. Subsequent activities of our IUPAC Subcommittee may focus on the measurement of these rate coefficients for other acrylates, including MA, on the development of standard protocols for determination of such coefficients, and on solvent effects on (meth)acrylate propagation. With all this information at hand, a complete picture of the propagation kinetics for the acrylate family will be available.

\section{Acknowledgements}

Financial support via the IUPAC-funded project 2011-034-2-400 is gratefully acknowledged.

\section{References}

1 O. F. Olaj, I. Bitai and F. Hinkelmann, Makromol. Chem., 1987, 188, 1689-1702.

2 M. Buback, R. G. Gilbert, R. A. Hutchinson, B. Klumperman, F.-D. Kuchta, B. G. Manders, K. F. O'Driscoll, G. T. Russell and J. Schweer, Macromol. Chem. Phys., 1995, 196, 32673280 .

3 S. Beuermann, M. Buback, T. P. Davis, R. G. Gilbert, R. A. Hutchinson, O. F. Olaj, G. T. Russell, J. Schweer and A. M. van Herk, Macromol. Chem. Phys., 1997, 198, 15451560.

4 S. Beuermann, M. Buback, T. P. Davis, R. G. Gilbert, R. A. Hutchinson, A. Kajiwara, B. Klumperman and G. T. Russell, Macromol. Chem. Phys., 2000, 201, 1355-1364.

5 S. Beuermann, M. Buback, T. P. Davis, N. García, R. G. Gilbert, R. A. Hutchinson, A. Kajiwara, M. Kamachi, I. Lacík and G. T. Russell, Macromol. Chem. Phys., 2003, 204, 1338-1350.

6 J. M. Asua, S. Beuermann, M. Buback, P. Castignolles, B. Charleux, R. G. Gilbert, R. A. Hutchinson, J. R. Leiza, A. N. Nikitin, J.-P. Vairon and A. M. van Herk, Macromol. Chem. Phys., 2004, 205, 2151-2160.

7 S. Beuermann, M. Buback, P. Hesse, F.-D. Kuchta, I. Lacík and A. M. van Herk, Pure Appl. Chem., 2007, 79, 1463-1469.

8 G. V. Schultz and J. Romatovski, Makromol. Chem., 1965, 85, 195-226.

9 A. N. Nikitin, P. Castignolles, B. Charleux and J. P. Vairon, Macromol. Rapid Commun., 2003, 24, 778-782.

10 A. N. Nikitin, R. A. Hutchinson, M. Buback and P. Hesse, Macromolecules, 2007, 40, 8631-8641.

11 G. E. Scott and E. J. Senogles, J. Macromol. Sci., Chem., 1970, A4, 1105-1117.

12 G. E. Scott and E. J. Senogles, J. Macromol. Sci., Rev. Macromol. Chem., 1973, C9, 49-69.

13 G. E. Scott and E. J. Senogles, J. Macromol. Sci., Chem., 1974, 8, 753-773.

14 N. M. Ahmad, F. Heatley and P. A. Lovell, Macromolecules, 1998, 31, 2822-2827.

15 J. Chiefari, J. Jeffery, R. T. A. Mayadunne, G. Moad, E. Rizzardo and S. H. Thang, Macromolecules, 1999, 32, 7700-7704.
16 C. Plessis, G. Arzamendi, J. M. Alberdi, A. M. van Herk, J. R. Leiza and J. M. Asua, Macromol. Rapid Commun., 2003, 24, 173-177.

17 T. Junkers and C. Barner-Kowollik, J. Polym. Sci., Part A: Polym. Chem., 2008, 46, 7585-7605.

18 D. Cuccato, E. Mavroudakis, M. Dossi and D. Moscatelli, Macromol. Theory Simul., 2013, 22, 127-135.

19 J. Vandenbergh and T. Junkers, Macromolecules, 2012, 45, 6850-6856.

20 C. Plessis, G. Arzamendi, J. R. Leiza, H. A. S. Schoonbrood, D. Charmot and J. M. Asua, Macromolecules, 2000, 33, 4-7.

21 R. X. E. Willemse, A. M. van Herk, E. Panchenko, T. Junkers and M. Buback, Macromolecules, 2005, 38, 5098-5103.

22 M. Buback, P. Hesse, T. Junkers, T. Sergeeva and T. Theis, Macromolecules, 2008, 41, 288-291.

23 J. Barth, M. Buback, P. Hesse and T. Sergeeva, Macromolecules, 2010, 43, 4023-4031.

24 C. Barner-Kowollik, F. Günzler and T. Junkers, Macromolecules, 2008, 41, 8971-8973.

25 T. Junkers, S. P. S. Koo, T. P. Davis, M. H. Stenzel and C. Barner-Kowollik, Macromolecules, 2007, 40, 8906-8912.

26 S. P. S. Koo, T. Junkers and C. Barner-Kowollik, Macromolecules, 2009, 42, 62-69.

27 T. Hirano and B. Yamada, Polymer, 2003, 44, 347-354.

28 T. Junkers, F. Bennet, S. P. S. Koo and C. Barner-Kowollik, J. Polym. Sci., Part A: Polym. Chem., 2008, 46, 34333437.

29 B. Manders, PhD thesis, TU Eindhoven, Eindhoven, The Netherlands, 1997.

30 R. A. Hutchinson, D. A. Paquet, Jr, J. H. McMinn, S. Beuermann, R. E. Fuller and C. Jackson, DECHEMA Monogr., 1995, 131, 467-492.

31 R. X. E. Willemse and A. M. van Herk, Macromol. Chem. Phys., 2010, 211, 539-545.

32 M. Buback, C. H. Kurz and C. Schmaltz, Macromol. Chem. Phys., 1998, 199, 1721-1727.

33 T. Junkers, M. Schneider-Baumann, S. P. S. Koo, P. Castignolles and C. Barner-Kowollik, Macromolecules, 2010, 43, 10427-10434.

34 P. Castignolles, Macromol. Rapid Commun., 2009, 30, 19952001.

35 P. Castignolles, R. Graf, M. Parkinson, M. Wilhelm and M. Gaborieau, Polymer, 2009, 50, 2373-2383.

36 C. M. Guttman, K. M. Flynn, W. E. Wallace and A. J. Kearsley, Macromolecules, 2009, 42, 1695-1702.

37 C. Y. Lin, E. I. Izgorodina and M. L. Coote, Macromolecules, 2010, 43, 553-560.

38 B. B. Noble and M. L. Coote, Int. Rev. Phys. Chem., 2013, 32, 467-513.

39 M. Buback, Macromol. Symp., 2009, 275-276, 90-101.

40 L. Couvreur, G. Piteau, P. Castignolles, M. Tongue, B. Coutin, B. Charleux and J. P. Vairon, Macromol. Symp., 2001, 174, 197-207.

41 S. Beuermann and M. Buback, Prog. Polym. Sci., 2002, 27, 191-254.

42 J. P. A. Heuts, R. G. Gilbert and L. Radom, Macromolecules, 1995, 28, 8771. 
43 S. Beuermann, M. Buback, P. Hesse and I. Lacik Macromolecules, 2006, 39, 184-193.

44 S. Beuermann, Macromol. Rapid Commun., 2009, 30, 10661088.
45 J. Barth, M. Buback, G. T. Russell and S. Smolne, Macromol. Chem. Phys., 2011, 212, 1366-1378.

46 T. Junkers, PhD thesis, Georg-August Universität Göttingen, Göttingen, Germany, 2006. 